\title{
Guanidino Compound Analysis as a Complementary Diagnostic Parameter for Hyperargininemia: Follow-Up of Guanidino Compound Levels during Therapy
}

\author{
B. MARESCAU, P. P. DE DEYN, A. LOWENTHAL, I. A. QURESHI, I. ANTONOZZI, \\ C. BACHMANN, S. D. CEDERBAUM, R. CERONE, N. CHAMOLES, J. P. COLOMBO, \\ K. HYLAND, R. GATTI, S. S. KANG, J. LETARTE, M. LAMBERT, N. MIZUTANI, \\ I. POSSEMIERS, I. REZVANI, S. E. SNYDERMAN, H. G. TERHEGGEN, AND M. YOSHINO \\ Laboratory of Neurochemistry, Born-Bunge Foundation and the Laboratory of Neuropharmacology, U.I.A., \\ University of Antwerp, Belgium ${ }^{1}$
}

\begin{abstract}
The aim of this collaborative study was to investigate whether guanidino compound analyses in the biologic fluids can be used as a complementary diagnostic parameter for hyperargininemia. Guanidino compounds were determined in the biologic fluids of all known living hyperargininemic patients using a cation exchange chromatographic system with a fluorescence detection method. The serum arginine, homoarginine, $\alpha$-keto- $\delta$-guanidinovaleric acid, argininic acid, and $\mathrm{N}-\alpha$-acetylarginine levels of all the hyperargininemic patients are higher than the normal range. Similar increases were seen for the urinary excretion of $\alpha$-keto- $\delta$-guanidinovaleric acid and argininic acid. Untreated hyperargininemic patients have the highest guanidino compound levels in cerebrospinal fluid. However, even under therapy, the arginine, homoarginine, $\alpha$ keto- $\delta$-guanidinovaleric acid, and argininic acid levels in cerebrospinal fluid are still increased. Protein restriction alone is not sufficient to normalize the hyperargininemia, but protein restriction together with supplementation of essential amino acids with or without sodium benzoate decreases further the arginine levels. However, whereas the argininemia can be normalized, the catabolites of arginine are still increased. We conclude that the urinary amino acid levels may remain normal in hyperargininemia, whereas consistent increases of the guanidino compounds are observed. Thus, guanidino compound analyses can be used as a complementary biochemical diagnostic parameter for hyperargininemia. Although the argininemia can be
\end{abstract}

Received June 20, 1989; accepted October 19, 1989

Correspondence and reprint requests Dr. B. Marescau, Department Geneeskunde, T 504, Universitaire Instelling Antwerpen, Universiteitsplein 1, $2610 \mathrm{An}$ twerpen, Belgium.

Supported by Fonds voor Geneeskundig Wetenschappelijk Onderzoek Gran 3.00019.86, the Ministerie voor Nationale Opvoeding en Nederlandse Cultuur Nationale Loterij Grant 9.0017.83, NATO Research Grant 83/0913, Concerted Action UIA Grant 84/89-68, the University of Antwerp, the Born-Bunge Foundation, M.R.C. Canada (M.A.9124), and St. Justine Hospital.

'Institutional affiliations of each author: B. Marescau, A. Lowenthal, P. P. De Deyn, and I. Possemiers; Laboratory of Neurochemistry, Born-Bunge Foundation (Antwerp), and Laboratory of Neuropharmacology, U.I.A. (Antwerp). I. A. Qureshi, J. Letarte, and M. Lambert; Hôpital Sainte Justine (Montreal). C. Bachmann Centre Hospitalier Universitaire Vaudois (Lausanne). J. P. Colombo; Inselspital Bern (Bern). R. Cerone and R. Gatti; Instituto G. Gaslini (Genova). I. Antonozzi Istitutio di Neuropsychiatria Infantile (Roma). S. D. Cederbaum; University of California (Los Angeles). N. Chamoles; Laboratory of Neurochemistry, Uriarte 2383 (Buenos Aires). K. Hyland; Institute of Child Health (London). S. S. Kang; Rush Presbytarian-St. Luke's Medical Center (Chicago). N. Mizutani; University of Nagoya, Medical School (Nagoya). I. Rezvani, St. Christopher's Hospital for Children (Philadelphia). S. E. Snyderman; New York University Medical Cente (New York). H. G. Terheggen; Maizweg 16 (Koln). M. Yoshino; Kurume University School of Medicine (Kurume). normalized by therapy, the levels of the catabolites of arginine are still elevated. (Pediatr Res 27: 297-303, 1990)

Deficiency of arginase, the last enzyme of the urea cycle, leads to hyperargininemia. The first clinical and biochemical descriptions of two sisters affected with hyperargininemia were published in 1969 (1) and 1970 (2, 3). Five y later, another sister was diagnosed shortly after birth (4). Since then, 19 other cases from 17 families have been reported (5-22). Patients with hyperargininemia present a neuropsychiatric syndrome consisting of varying degrees of mental retardation, epilepsy, and progressive spasticity. This latter symptom is at variance with other defects of the urea cycle. Some patients have, in addition, recurrent episodes of vomiting and irritability accompanied by moderate hyperammonemia. As a consequence of the arginase deficiency, the patients accumulate excessive arginine. Some secondary catabolites of arginine, guanidino compounds, are massively excreted in the urine of these patients (23). Figure 1 shows some proposed catabolic pathways of arginine in patients with hyperargininemia.

In hyperargininemia it is unclear whether ammonia is the principal toxin. Indeed, the presence of normal or only slightly elevated ammonia levels has been demonstrated in several patients $(6,7,9,15)$, and the progressive spasticity typically encountered in hyperargininemia is not observed in the other urea cycle disorders. Therefore, the role of arginine and its metabolites, the guanidino compounds, as candidate neurotoxins has been proposed. Furthermore, many guanidino compounds have been shown experimentally to be epileptogenic (24-26).

As patients with other urea cycle disorders, hyperargininemic patients impose protein restriction upon themselves (5). Protein restriction was also the first approach to therapy of hyperargininemia $(2,5)$. With the therapeutic evolution in the other urea cycle disorders, additional approaches were introduced in hyperargininemic patients with the intention of bypassing the defective urea cycle. Most promising results were obtained by Snyderman et al. (8), who prevented neurologic complications by treating a boy from the day of birth with protein restriction and supplementation of essential amino acids. In the two siblings of this patient, even a significant decrease of neurologic complications occurred after institution of the same therapy (5). The administration of sodium benzoate, which diverts ammonia nitrogen from the defective urea cycle pathway to the hippurate biosyn- 


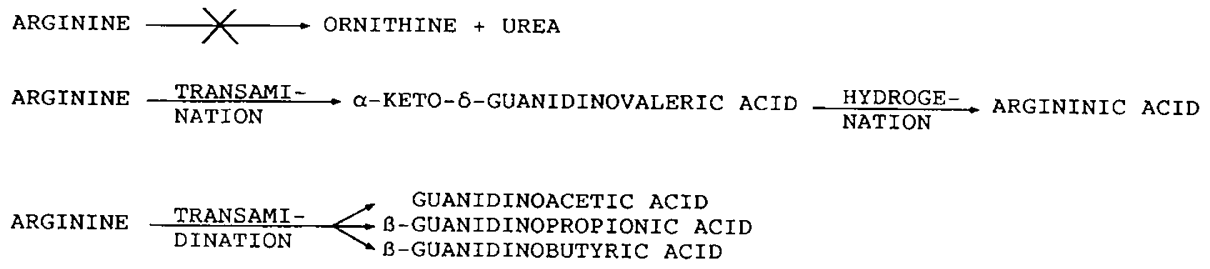

ARGININE $\stackrel{\text { ACETYLATION }}{\longrightarrow} \mathrm{N}-\alpha-$ ACETYLARGININE

Fig. 1. Proposed catabolic pathways of arginine in patients with hyperargininemia.

Table 1. Normal range of the guanidino compounds in human serum, urine, and cerebrospinal fluid (CSF)

\begin{tabular}{lccc}
\hline \multicolumn{1}{c}{ Guanidino compounds } & $\begin{array}{c}\text { Serum }(\mu \mathrm{M}) \\
(n=107)\end{array}$ & $\begin{array}{c}\text { Urine } \\
(\mu \text { mol/g creatinine }) \\
(n=30)\end{array}$ & $\begin{array}{c}\text { CSF }(\mu \mathrm{M}) \\
(n=45)\end{array}$ \\
\hline$\alpha$-keto- $\delta$-guanidinovaleric acid & $<0.050$ & $<$ DL*-30 & $<0.025$ \\
Guanidinosuccinic acid & $0.100-0.500$ & $15-160$ & $0.020-0.150$ \\
Creatine & $10-200$ & $35-90$ & $0.015-0.100$ \\
Guanidinoacetic acid & $0.400-3.00$ & $100-2050$ & $0.030-0.200$ \\
N- $\alpha$-acetylarginine & $<0.025-0.255$ & $10-100$ & $<0.013-0.070$ \\
Argininic acid & $<0.025-0.100$ & $1-30$ & $<0.013$ \\
$\beta$-guanidinopropionic acid & $<0.025-0.084$ & $<$ DL-0.260 & $30-130$ \\
Creatinine & $10-100$ & $5-40$ & $<0.013-0.100$ \\
$\gamma$-guanidinobutyric acid & $<0.025-0.087$ & $2-100$ & $13-30$ \\
Arginine & $40-155$ & $<\mathrm{DL}-20$ & $0.120-0.600$ \\
Homoarginine & $<0.500-2.80$ & $3-35$ & $<0.100$ \\
Guanidine & $<0.200-0.400$ & $1-12$ & $<0.050$ \\
Methylguanidine & $<0.100$ & & \\
\hline
\end{tabular}

* Detection limit.

thesis pathway, has also been found to be beneficial in ammonia detoxification (27). Lambert et al. (28) demonstrated an arrest in the developing spasticity and an increase of mental acuity in one patient subjected to such treatment.

We started this collaborative study to investigate whether the guanidino compounds can furnish complementary diagnostic parameters for hyperargininemia that can remain undiagnosed by urinary amino acid analysis only (5). We present the followup of the serum guanidino compound levels during $8 \mathrm{y}$ of therapy in a hyperargininemic patient.

\section{MATERIALS AND METHODS}

Patients. Twenty-two cases have been published. The patients described by Jorda et al. (19), Endres et al. (16), and Sakiyama et al. (12) have died. No biologic fluids from these patients were available for this study. The patient of Antonozzi and coworkers $(20,21)$, from which plasma and urine were included in this study, died a few weeks after sampling, as a consequence of an acute febrile illness with status epilepticus. Samples were collected from each of the living, published cases. Their clinical and biochemical descriptions have been reported earlier (5-22). Eight unpublished cases were included as well: two cases of Dr. I. A. Qureshi (Montreal), two cases of Dr. C. Bachmann (Lausanne) and Dr. Colombo (Bern), one case of Dr. I. Rezvani and Dr. M. Batshaw (Philadelphia); one case of Dr. Edwards (Birmingham), one case of Dr. N. Chamoles (Buenos Aires), and one case of Dr. R. Gatti (Genova). We were unable to collect both serum and urine as well as cerebrospinal fluid from each patient. In this study 25 urine, 19 serum, and seven cerebrospinal fluid samples of different hyperargininemic patients were collected. For the purposes of the study, one would ideally consider samples of untreated patients. However, it is medically and ethically unacceptable to interrupt the therapies. Therefore, samples of patients under no treatment $(n=2)$, protein restriction $(n=10)$, or combined therapy of protein restriction with supplementation of essential amino acids with $(n=8)$ or without $(n=6)$ sodium benzoate were included in this study. Doses of the commercial arginine-free essential amino acid mixtures, ranging from 0.4 $0.7 \mathrm{~g} / \mathrm{kg} / \mathrm{d}$, were given to the patients. When sodium benzoate was administered, doses of $250 \mathrm{mg} / \mathrm{kg} / \mathrm{d}$ were given. One patient was on a protein restricted diet together with essential amino acids and a supplementation of ornithine $(100 \mathrm{mg} / \mathrm{kg} / \mathrm{d})$ and lysine $(250 \mathrm{mg} / \mathrm{kg} / \mathrm{d})(14)$. From the 26 hyperargininemic patients two were younger than $2 \mathrm{y}$ and one was an adult at the time of sampling. The others were children $(n=15,2$ y to puberty) and adolescents ( $n=8$, puberty to $18 \mathrm{y}$ ).

The patients were only included after informed consent was obtained in accordance with the principles of the declaration of Helsinki.

Controls. The age-matched control group for serum and urinary values consisted of healthy volunteers and patients admitted to the hospital for minor surgery and were without history of neurologic, metabolic, or renal disease. Sampling was done before surgery after overnight fasting. The control group for normal cerebrospinal fluid levels was comprised of patients presenting with neurologic complaints in whom, however, after performing a series of clinical and neurochemical diagnostic tests, no neurologic, metabolic, or renal disease was diagnosed.

Collection and preparation of samples. Sampling was done in the morning. The procedure for collection and preparation of serum and cerebrospinal fluid samples has been reported (29). Equal volumes of a $200 \mathrm{~g} / \mathrm{L}$ trichloroacetic acid solution were mixed with urine and centrifuged in a Beckman microfuge (Beckman Instruments Inc., Fullerton, CA). Clear supernatant was diluted and used for guanidino compound analysis.

Laboratory methods. The concentration of the guanidino compounds was determined using a Biotronic LC 6001 amino acid analyzer (Biotronic GmbH, Maintal, FRG) adapted for guanidino compound determination. The guanidino compounds were separated over a cation exchange column using sodium citrate buffers and were detected with the fluorescence ninhydrin 

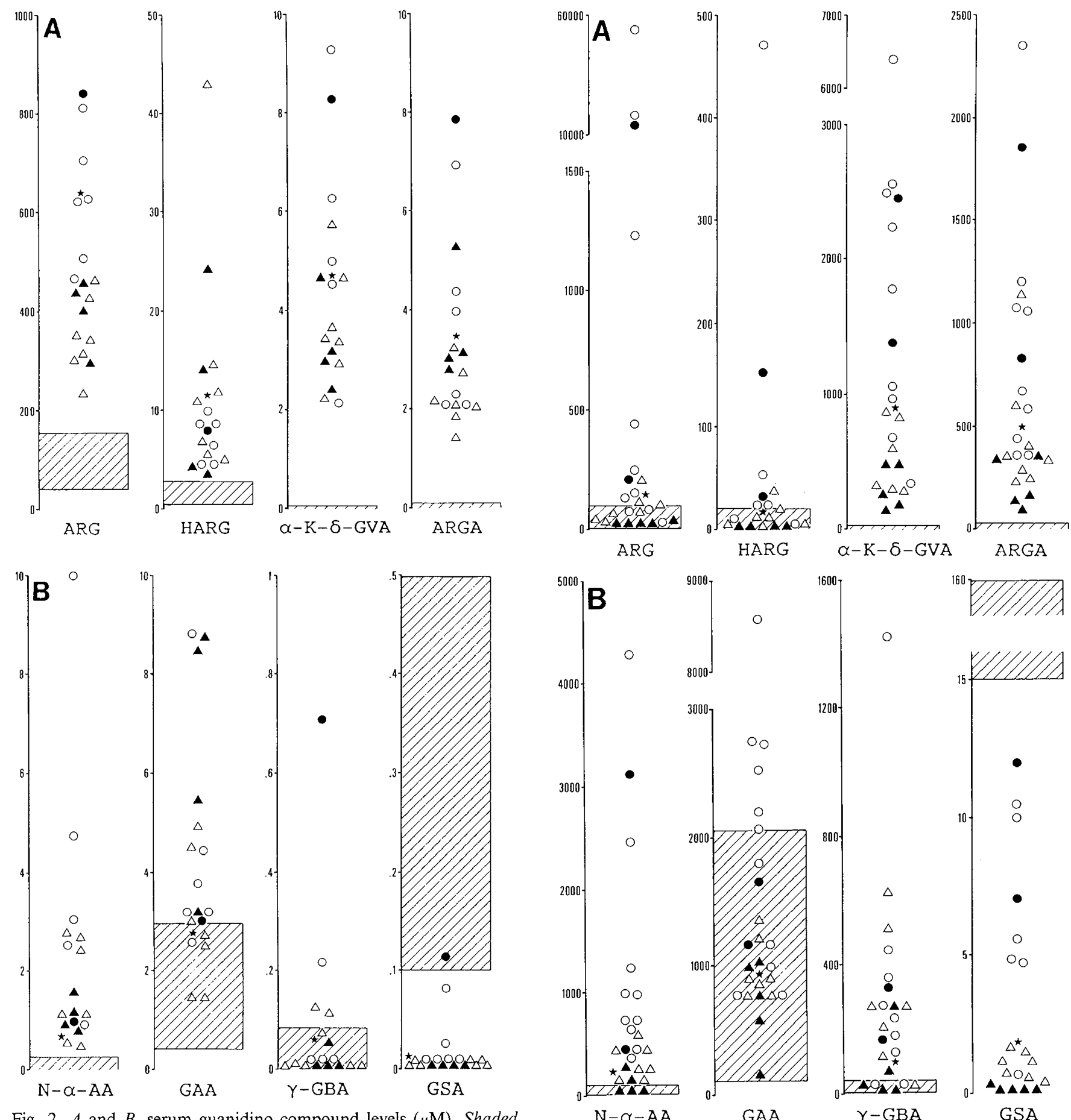

Fig. 2. $A$ and $B$, serum guanidino compound levels $(\mu \mathrm{M})$. Shaded areas, range of normal values. $A R G$, arginine; $H A R G$, homoarginine; $\alpha$ $\mathrm{K}$ - $\delta$-GVA, $\alpha$-Keto- $\delta$-guanidino-valeric acid; ARGA, argininic acid; $\mathrm{N}-\alpha$ AA, $\mathrm{N}$ - $\alpha$-acetylarginine; GAA, guanidinoacetic acid; $\gamma$-GBA, $\gamma$-guanidinobutyric acid; GSA, guanidinosuccinic acid. Free diet $(n=1) \bullet$; protein restriction $(n=6) \bigcirc$; protein restriction + essential amino acids $(n=4)$ $\Delta$; protein restriction + essential amino acids + sodium benzoate $(n=$ 7) $\Delta$; protein restriction + essential amino acids + Orn and Lys $(n=1)$ $\star$. Eleven of 18 hyperargininemic patients have $\gamma$-guanidinobutyric acid levels below detection limit and all but three have guanidinosuccinic acid levels lower than the detection limit.

method $(30,31)$. Table 1 lists the 13 guanidino compounds determined and their normal levels in serum, urine, and cerebrospinal fluid. It was our purpose to study the guanidino compound levels as a complementary diagnostic parameter for hyperargininemia, and we present in the figures the range values of all the studied controls.

Fig. 3. $A$ and $B$, urinary guanidino compound levels ( $\mu \mathrm{mol} / \mathrm{g}$ creatinine). Shaded areas $=$ range of normal values. For abbreviations see Figure 2. Free diet $(n=2)$; protein restricion $(n=10) \bigcirc$; protein restriction + essential amino acids $(n=5) \boldsymbol{\Delta}$; protein restriction + essential amino acids + sodium benzoate $(n=7) \Delta$; protein restriction + essential amino acids + Orn and Lys $(n=1) \star$. Four patients under a combined therapy of protein restriction together with essential amino acids excreted guanidinosuccinic acid and homoarginine levels lower than the detection limit.

\section{RESULTS}

Guanidino compounds in serum, urine, and cerebrospinai fluid. From the 13 guanidino compounds quantitated in serum of hyperargininemic patients, the levels of $\beta$-guanidinopropionic acid, guanidine, and methylguanidine were below the detection 
Table 2. Mean levels and SD of some guanidino compounds in serum of treated and untreated hyperargininemic patients $(\mu M)^{*+}$

\begin{tabular}{lccc}
$\begin{array}{l}\text { Guanidino } \\
\text { compound }\end{array}$ & $\begin{array}{c}\mathrm{FD}+\mathrm{PR} \\
(n=7)\end{array}$ & $\begin{array}{c}\mathrm{PR}+\mathrm{EAA} \\
(n=4)\end{array}$ & $\begin{array}{c}\mathrm{PR}+\mathrm{EAA}+\mathrm{SB} \\
(n=7)\end{array}$ \\
\hline$\alpha-\mathrm{K}-\delta$-GVA & $5.90 \pm 2.62$ & $3.30 \pm 0.96$ & $3.70 \pm 1.15$ \\
GAA & $4.10 \pm 2.17$ & $6.40 \pm 2.66$ & $2.90 \pm 1.36$ \\
$\mathrm{~N}-\alpha-\mathrm{AA}$ & $3.70 \pm 3.51$ & $1.10 \pm 0.37$ & $1.60 \pm 1.02$ \\
Arg A & $4.23 \pm 2.37$ & $3.60 \pm 1.15$ & $2.20 \pm 0.59$ \\
Arg & $652 \pm 142$ & $396 \pm 71.7 \ddagger$ & $345 \pm 76.6 \ddagger$ \\
HArg & $7.16 \pm 2.12$ & $11.5 \pm 9.63$ & $13.9 \pm 13.3$ \\
\hline
\end{tabular}

* For abbreviations of guanidino compounds see Figure 2.

$\dagger$ FD, free diet; PR, protein restriction; EAA, essential amino acids; $\mathrm{SB}$, sodium benzoate.

$\ddagger$ Significantly different from the group of untreated and protein restricted $(\mathrm{FD}+\mathrm{PR})$ patients $(p<0.01)$.

Table 3. Mean excretion levels and SD of some guanidino compounds in urine of treated and untreated hyperargininemic patients ( $\mu$ mol/g creatinine) ${ }^{*} \uparrow$

\begin{tabular}{lccc}
\hline $\begin{array}{c}\text { Guanidino } \\
\text { compounds }\end{array}$ & $\begin{array}{c}\text { FD }+ \text { PR } \\
(n=12)\end{array}$ & $\begin{array}{c}\text { PR }+ \text { EAA } \\
(n=5)\end{array}$ & $\begin{array}{c}\text { PR + EAA + SB } \\
(n=7)\end{array}$ \\
\hline$\alpha$-K- $\delta$-GVA & $2034 \pm 1646$ & $308 \pm 161 \ddagger$ & $540 \pm 268 \ddagger$ \\
GSA & $6.87 \pm 3.86$ & $0.24 \pm 0.09 \ddagger$ & $1.06 \pm 0.47 \S$ \\
GAA & $2263 \pm 2118$ & $705 \pm 347 \ddagger$ & $963 \pm 221 \S$ \\
N- $\alpha-A A$ & $1365 \pm 1249$ & $127 \pm 96 \ddagger$ & $325 \pm 154 \ddagger$ \\
Arg A & $926 \pm 637$ & $221 \pm 121 \ddagger$ & $465 \pm 324 \S$ \\
$\gamma$-GBA & $301 \pm 397$ & $76 \pm 109 \S$ & $289 \pm 212$ \\
Arg & $7451 \pm 16022$ & $24 \pm 10 \ddagger$ & $92 \pm 62 \S$ \\
HArg & $96 \pm 160$ & $1.32 \pm 0.72 \ddagger$ & $12 \pm 13 \S$ \\
\hline
\end{tabular}

* For abbreviations of guanidino compounds see Figure 2.

$\dagger$ Four of the five patients under a combined therapy of protein restriction together with essential amino acids excreted GSA and HArg levels lower than the detection limit. However, to be able to do statistic evaluations we used a value of $0.20 \mu \mathrm{mol} / \mathrm{g}$ creatinine for GSA and 1 $\mu \mathrm{mol} / \mathrm{g}$ creatinine for HArg. These values are half that of the lowest excreted GSA and HArg levels in urine of all the hyperargininemic patients in this study.

$\ddagger$ Significantly different from the group of untreated and protein restricted (FD + PR) patients $(p<0.01)$.

$\S$ Significantly different from the group of untreated and protein restricted $(\mathrm{FD}+\mathrm{PR})$ patients $(p<0.05)$.

limit in all patients and comparable to controls. The serum levels of creatine and creatinine were within the normal range for all the hyperargininemic patients. Therefore these five guanidino compounds are not included in Figure 2. The serum arginine, homoarginine, $\alpha$-keto- $\delta$-guanidinovaleric acid, argininic acid, and $\mathrm{N}-\alpha$-acetylarginine levels of all the hyperargininemic patients were higher than the normal range. The serum guanidinoacetic acid levels of some hyperargininemic patients fell within the normal range. The $\gamma$-guanidinobutyric acid levels of most of the studied hyperargininemic patients were comparable to controls. However, the serum guanidinosuccinic acid levels of most of the hyperargininemic patients were below control. The considerable patient-to-patient variations in the levels of the serum guanidino compounds are probably a consequence of the therapy. Proving this by statistical analysis is difficult because of a wide range of the individual values in each group. However, we have attempted to make this comparison in Table 2 by using nonparametric methods (Mann-Whitney test). For the purpose of this comparison, the untreated and protein-restricted hyperargininemic patients have been considered as one group because hyperargininemic patients, as with the other urea cycle patients, mostly impose upon themselves a restricted protein diet. Untreated and protein-restricted hyperargininemic patients had mostly higher serum arginine, $\alpha$-keto- $\delta$-guanidinovaleric acid, argininic acid, and $\mathrm{N}$ - $\alpha$-acetylarginine levels than those under a combined therapy of protein restriction together with a supplementation of essential amino acids with or without sodium benzoate. The serum homoarginine levels of the hyperargininemic patients under a combined therapy had a tendency to be higher than those of the untreated and protein-restricted patients. This is probably in relation with the fact that the essential amino acid supplementation contains lysine, a metabolic precursor of homoarginine $(32,33)$. The patient-to-patient variations in the levels of $\gamma$-guanidinobutyric acid and guanidinosuccinic acid are difficult to interpret because most were under the detection limit.

The urinary excretion of guanidine, methylguanidine, and creatine were within the normal range for all the studied hyperargininemic patients. The excretion of $\beta$-guanidinopropionic acid from most of the 25 patients was also comparable to controls, but eight were abnormal: seven had excretion about four times and one about 15 times higher than the upper limit of the controls. These four guanidino compounds are not included in Figure 3. The urinary excretion of $\alpha$-keto- $\delta$-guanidinovaleric acid and argininic acid of all the studied hyperargininemic patients were higher than the normal range. The urinary excretion of $\mathrm{N}$ $\alpha$-acetylarginine and $\gamma$-guanidinobutyric acid of most of the patients were higher than normal, but the majority had arginine, homoarginine, and guanidinoacetic acid excretion within the normal range. As for the serum values, the urinary excretion of guanidinosuccinic acid of all the studied hyperargininemic patients were lower than the control levels. The considerable patient-to-patient variations in the urinary excretion of the guanidino compounds are probably, as in serum, also a consequence of the therapy. Statistical analyses are again difficult because of the wide range of the individual values in each group.However, we have attempted to make this comparison in Table 3 by using again the Mann-Whitney test. The untreated and protein-restricted hyperargininemic patients have been put in the same group; they had higher urinary excretion of arginine, homoarginine, $\alpha$-keto- $\delta$-guanidinovaleric acid, argininic acid, $\mathrm{N}$ - $\alpha$-acetylarginine, guanidinoacetic acid, and guanidinosuccinic acid compared to patients under a combined therapy of protein restriction with a supplementation of essential amino acids, with or without sodium benzoate.

The cerebrospinal fluid levels of creatine, guanidinoacetic acid, $\beta$-guanidinopropionic acid, creatinine, $\gamma$-guanidinobutyric acid, guanidine, and methylguanidine of all the patients were within the normal range, except for the untreated hyperargininemic patient, who had $\gamma$-guanidinobutyric acid and guanidine levels about 10 times higher than the upper limit of controls (data not shown). The untreated hyperargininemic patient had the highest levels of arginine, $\alpha$-keto- $\delta$-guanidinovaleric acid, argininic acid, $\mathrm{N}$ - $\alpha$-acetylarginine (Fig. 4). However, the homoarginine level in cerebrospinal fluid of the untreated patient was the lowest. The tendency to higher cerebrospinal fluid homoarginine levels in hyperargininemic patients receiving an essential amino acid mixture could be related to lysine, which can be a metabolic precursor of homoarginine. Figure 4 also shows that even under therapy, the arginine, homoarginine, $\alpha$-keto- $\delta$-guanidinovaleric acid, and argininic acid levels in cerebrospinal fluid of hyperargininemic patients are still higher than in controls.

Serum guanidino compound levels during therapy. Figure 5 shows the follow-up of the serum guanidino compound levels during $8 \mathrm{y}$ of therapy in one hyperargininemic patient. Only through restriction of the daily arginine intake (protein restriction and supplementation of essential amino acids without arginine) the serum arginine levels could be lowered to the upper limit of the control range. During the first years (1982-1984) of a combined therapy of protein restriction together with a supplementation of essential amino acids with sodium benzoate, the serum guanidinoacetic acid and $\mathrm{N}-\alpha$-acetylarginine levels were brought into the upper control levels. However, a longer follow-up shows that these guanidino compound levels could not be normalized. The decrease and the normalization of the serum arginine levels could certainly not normalize the serum $\alpha$-keto- $\alpha$-guanidinov- 

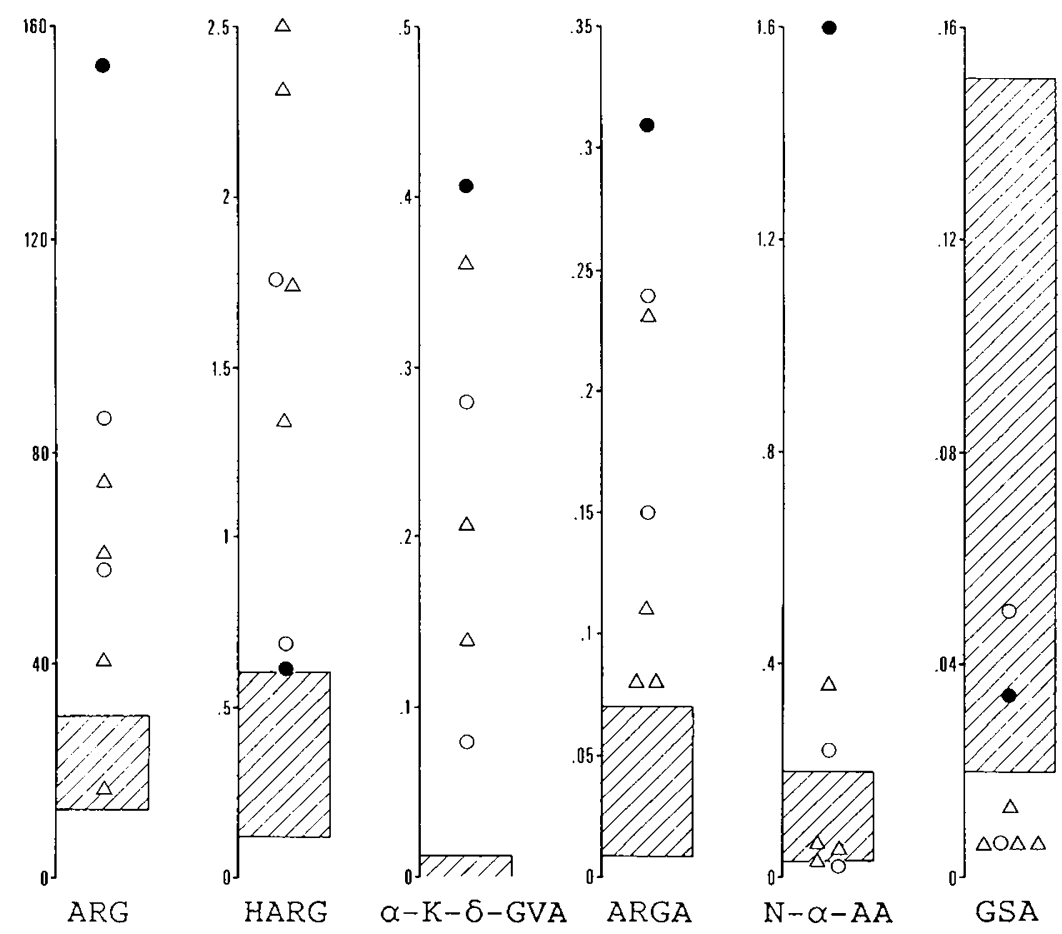

Fig. 4. Cerebrospinal fluid guanidino compound levels $(\mu \mathrm{M})$. Shaded areas $=$ range of normal values. For abbreviations see Figure 2 . Free diet $(n=1)$; protein restriction $(n=2) \bigcirc$; protein restriction + essential amino acids + sodium benzoate $(n=4) \triangle$. Four patients have guanidinosuccinic acid levels lower than the detection limit.

aleric acid, argininic acid, and homoarginine levels, which remained considerably increased.

\section{DISCUSSION}

Quantitative determination of guanidino compounds in the biologic fluids of hyperargininemic patients shows that some guanidino compounds are greatly increased. As a consequence of the arginase deficiency the serum arginine and homoarginine levels are increased. Taking into account the upper control limits (Table 1), it seems that the secondary catabolic pathway that is most activated in hyperargininemic patients is the one with the formation of $\alpha$-keto- $\delta$-guanidinovaleric acid. The increase in serum is about 100 -fold. This formation is probably catalyzed by a transaminase. The increased activity of the hydrogenation of $\alpha$-keto- $\delta$-guanidinovaleric to argininic acid is also remarkable. The increase of the transamidination activity involved in the biosynthesis of guanidinoacetic acid, $\gamma$-guanidinobutyric acid, and $\beta$-guanidinopropionic acid in hyperargininemic patients is less pronounced. It must also be stressed that the transamidination of arginine with $\gamma$-guanidinobutyric acid formation can always be overestimated in hyperargininemic patients. Indeed, $\alpha$-keto- $\delta$-guanidinovaleric acid is an unstable product and degrades partially to $\gamma$-guanidinobutyric acid by chemical oxidation (34). Therefore the time between sampling and analysis must be as short as possible to prevent overestimation of the $\gamma$-guanidinobutyric acid and an underestimation of the $\alpha$-keto- $\delta$-guanidinovaleric acid levels.

The biosynthesis of guanidinosuccinic acid is related to urea (35). This is reflected in the Figures $2 B, 3 B$, and 4 : untreated and protein-restricted hyperargininemic patients probably have higher guanidinosuccinic acid levels in their biologic fluids than those under a combined therapy of protein restriction together with essential amino acid supplementation with or without sodium benzoate. Hyperargininemic patients have a decreased urea cycle activity. Protein restriction and supplementation of essential amino acids further decrease the urea cycle activity. The urea biosynthesis is also decreased by administration of sodium benzoate.
The abnormal catabolism of arginine leads to an accumulation of some secondary catabolites in serum as well as in cerebrospinal fluid. The results of Figure $2 A$ and $B$ and Figure $3 A$ and $B$ demonstrate that the quantitative determination of the guanidino compounds has complementary diagnostic implications in hyperargininemia. Early diagnosis is very important to prevent neurologic complications (8). At present hyperargininemia is biochemically diagnosed by increased arginine levels in serum. The diagnosis can be confirmed by measuring the arginase activity in erythrocytes. Determination of arginine in urine alone can yield a false-negative diagnosis. Indeed, some untreated hyperargininemic patients have urinary arginine excretion levels around the upper normal levels, whereas serum arginine levels are increased. These patients also do not show a secondary lysinecystinuria pattern seen in others. They can remain undiagnosed by urinary amino acid analysis only (5). Even if a lysine-cystinuria pattern is seen, the diagnosis must be confirmed by serum arginine determinations. However, in urine of hyperargininemic patients with normal urinary arginine levels, the excretion levels of $\alpha$-keto- $\delta$-guanidinovaleric acid and argininic acid are clearly increased. It must be stressed again that in this collaborative study more than half of the hyperargininemic patients were under a combined therapy of protein restriction together with essential amino acid supplementation with or without sodium benzoate. Still higher guanidino compound levels are to be expected in the biologic fluids of untreated patients.

The interpatient study as well as the intrapatient study presented in this report suggest that protein restriction alone is not sufficient to normalize the hyperargininemia. Only a combined therapy of protein restriction together with a supplementation of essential amino acids with or without sodium benzoate seems to be efficacious in further decreasing the arginine levels in the biologic fluids. However, it must be stressed that when the argininemia could be normalized, these arginine levels in serum are still too high for hyperargininemic patients with an abnormal arginase activity, which results in still abnormal levels of the catabolites of arginine. If it is proven that the accumulated guanidino compounds have an influence or are partially responsible for some neurologic symptoms seen in hyperargininemic 

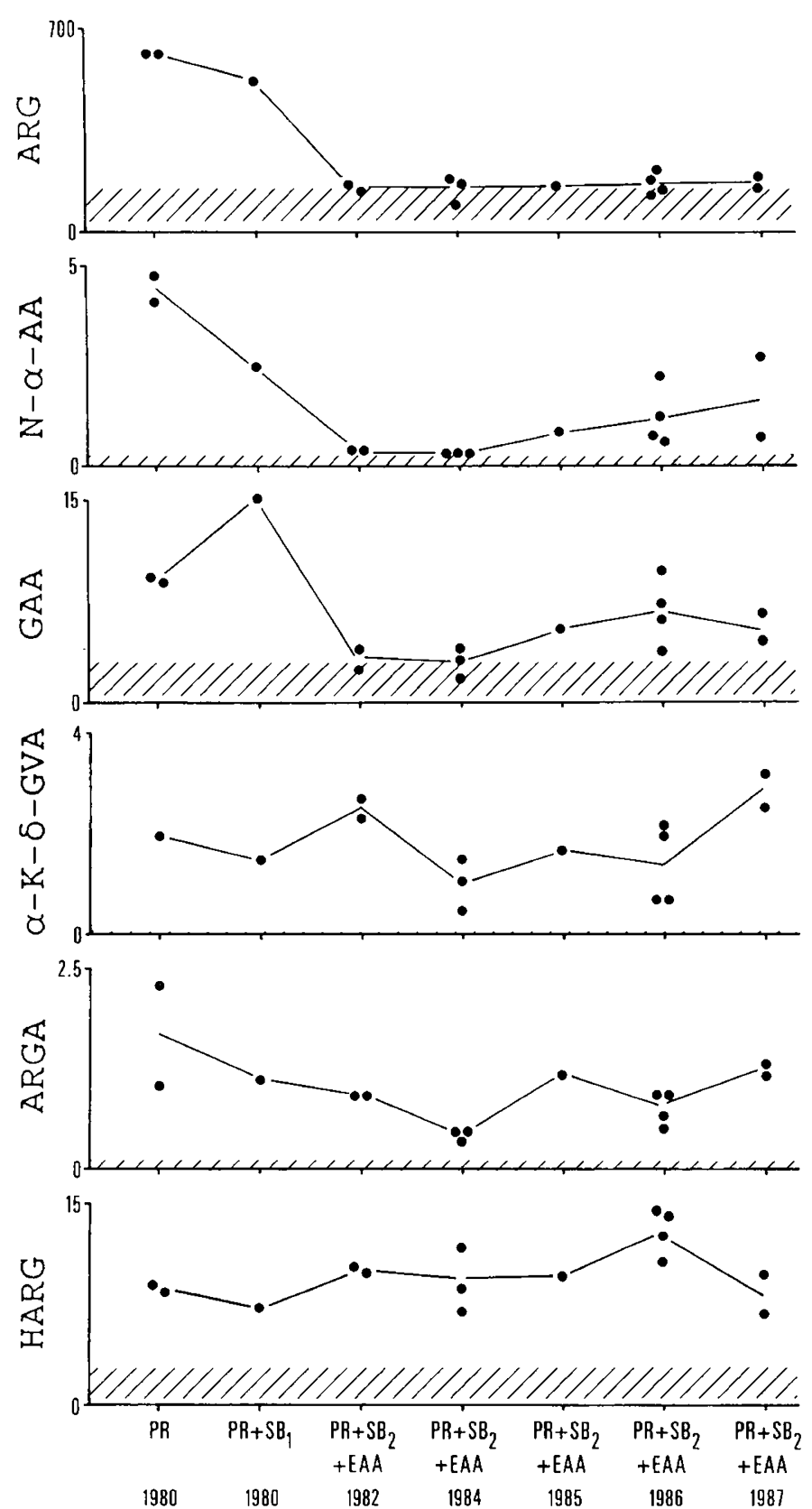

Fig. 5. Follow-up of the serum guanidino compound levels during 8 $y$ of therapy in a hyperargininemic patient. For abbreviations of guanidino compounds see Figure 2. The serum $\alpha$-keto- $\delta$-guanidinovaleric acid levels in controls are lower than the detection limit $(<0.05 \mu \mathrm{M}) . P R$, protein restriction; $\mathrm{PR}+\mathrm{SB} 1$, protein restriction + sodium benzoate 250 $\mathrm{mg} / \mathrm{kg} / \mathrm{d} ; \mathrm{PR}+\mathrm{SB} 2+\mathrm{EAA}$, protein restriction + sodium benzoate 350 $\mathrm{mg} / \mathrm{kg} / \mathrm{d}+$ essential amino acids.

patients, then dietary and medical treatment should also focus on efforts to decrease the guanidino compound levels other than arginine. Prevention and/or decrease of neurologic complications obtained by institution of a protein restriction together with a supplementation of essential amino acids with or without sodium benzoate $(6,8,28)$, coincided with a substantial lowering of the guanidino compounds and further support the hypothesis that guanidino compounds are neurotoxins in hyperargininemia. Therefore, it seems indicated also to perform guanidino compound determinations for each patient, especially with each change in therapeutic regimen, in an attempt to lower these toxins as much as possible.
Acknowledgments. The authors thank Drs. M. L. Batshaw, A. L. Beaudet, and M. E. Edwards who provided us with samples. Furthermore, we also thank Dr. M. L. Batshaw for his valuable suggestions for improvement of the manuscript.

\section{REFERENCES}

1. Terheggen HG, Schwenk A, Lowenthal A, van Sande M, Colombo JP 1969 Argininemia with arginase deficiency. Lancet 2:748-749

2. Terheggen HG, Schwenk A, Lowenthal A, van Sande M, Colombo JP 1970 Hyperargininämie mit Arginasedefekt. Eine neue familiäre Stoffwechselströrung. I. Klinische Befunde. Z Kinderheilk 107:298-312

3. Terheggen HG, Schwenk A, Lowenthal A, van Sande M, Colombo JP 1970 Hyperargininämie mit Arginasedefekt. Eine neue familiäre Stoffwechselstörung. II. Biochemische Untersuchungen. Z Kinderheilk 107:312-323

4. Terheggen HG, Lowenthal A, Lavinha F, Colombo JP 1975 Familial hyperargininemia. Arch Dis Child 50:57-62

5. Cederbaum SD, Shaw KNF, Valente M 1977 Hyperargininemia. J Pediatr 90:569-573

6. Snyderman SE, Sansaricq C, Chen WJ, Norton PM, Phansalkar SV 1977 Argininemia. J Pediatr 90:563-568

7. Michels VV, Beaudet AL 1978 Arginase deficiency in multiple tissues in argininemia. Clin Genet 13:61-67

8. Snyderman SE, Sansaricq C, Norton PM, Goldstein F 1979 Argininemia treated from birth. J Pediatr 95:61-63

9. Cederbaum SD, Shaw KNF, Spector EB, Verity MA, Snodgrass PJ, Sugarman GI 1979 Hyperargininemia with arginase deficiency. Pediatr Res 13:827833

10. Qureshi IA, Letarte J, Ouellet R, Lelièvre M, Laberge C 1981 Ammonemia metabolism in a family affected by hyperargininemia. Diabet Metab 7:5-11

11. Yoshino M, Kubota K, Yoshida I, Murakami T, Yamashita F 1982 Argininemia: report of a new case and mechanisms of orotic aciduria and hyperammonemia. In: Lowenthal A, Mori A, Marescau B (eds) Urea Cycle Diseases. Plenum Press, New York, pp 121-125

12. Sakiyama T, Nakabayashi H, Kondo Y, Shimizu H, Kodama S, Kitagawa T 1982 Argininemia: clinical course and trial of enzyme replacement therapy. Biomed Therapeut (Tokyo) 8:907-910

13. Mizutani N, Maehara M, Hayakawa C, Kato T, Watanabe K, Suzuki S 1983 Hyperargininemia: clinical course and treatment with sodium benzoate and phenylacetic acid. Brain Dev 5:553-563

14. Kang SS, Wong PWK, Melyn MA 1983 Hyperargininemia: effect of ornithine and lysine supplementation. J Pediatr 103:763-765

15. Qureshi IA, Letarte J, Quellet R, Larochelle J, Lemieux B 1983 A new FrenchCanadian family affected by hyperargininemia. J Inherited Metab Dis 6:179182

16. Endres W, Schaller R, Shin YS 1984 Diagnosis and treatment of argininemia. Characteristics of arginase in human erythrocytes and tissues. $\mathbf{J}$ Inherited Metab Dis 7:8

17. Bernar J, Hanson RA, Kern R, Phoenix B, Shaw KNF, Cederbaum SD 1986 Arginase deficiency in a 12-year-old boy with mild impairment of intellectual function. J Pediatr 108:432-435

18. Hyland K, Smith I, Clayton PT, Leonard JV 1986 Impaired neurotransmitter amine metabolism in arginase deficiency. J Neurol Neurosurg Psychiatr 49:1188-1189

19. Jorda A, Rubio V, Portoles M, Vilas J, Garcia-Pino J 1986 A new case of arginase deficiency in a Spanish male. J Inherited Metab Dis 9:393-397

20. Antonozzi I, Leuzzi V, Lombardo Radice M, Porro G 1986 Iperagininemia: descrizione di un caso-hyperargininemia: report of a case. Riv Ital Ped (IJP) 12:270-274

21. Antonozzi I, Leuzzi V 1987 Hyperargininemia. J Inherited Metab Dis 10:200

22. Romano C, Pescetto T, Caruso V, Cerone R, Caffarena G 1987 Clinical and biochemical studies on a new patient affected by argininemia. Persp Inherited Metab Dis 7:19-22

23. Terheggen HG, Lavinha F, Colombo JP, van Sande M, Lowenthal A 1972 Familial hyperargininemia. J Genet Hum 20:69-84

24. Mori A 1987 Biochemistry and neurotoxicology of guanidino compounds. History and recent advances. Pavlov J Biol Sci 22:85-94

25. Marescau B, Hiramatsu M, Mori A $1983 \alpha$-Keto- $\delta$-guanidinovaleric acid induced electroencephalographic epileptiform discharges in rabbits. Neurochem Pathol 1:203-209

26. De Deyn PP, Marescau B, Macdonald RL 1988 Effects of $\alpha$-keto- $\delta$-guanidinovaleric acid on inhibitory amino acid responses on mouse neurons in cell culture. Brain Res 449:54-60

27. Qureshi IA, Letarte J, Ouellet R, Batshaw ML, Brusilow S 1984 Treatment of hyperargininemia with sodium benzoate and arginine restricted diet. J Pediat 104:473-476

28. Lambert MA, Desjardins M, Ogier H, Qureshi I, Marescau B, Lowenthal A 1988 Guanidino compounds and neurotransmitter amines in the CSF of a hyperargininemic patient during therapy. Am J Hum Genet 43(suppl A11)(abstr)

29. De Deyn PP, Marescau B, Cuykens J, Van Gorp L, Lowenthal A, De Potter WP 1987 Guanidino compounds in serum and cerebrospinal fluid of nondialyzed patients with renal insufficiency. Clin Chim Acta 167:81-88

30. Marescau B, Quereshi IA, De Deyn P, Letarte J, Ryba R, Lowenthal A 1985 Guanidino compounds in plasma, urine and cerebrospinal fluid of hyperargininemic patients during therapy. Clin Chim Acta 146:21-27 
31. Marescau B, De Deyn P, Van Gorp L, Lowenthal A 1986 Purification procedure for some urinary guanidino compounds. J Chromatogr 337:334-338

32. Ryan WL, Wells IC 1964 Homocitrulline and homoarginine synthesis from lysine. Science 144:1122-1125

33. Scott-Emuakpor A, Higgins JV, Kohrman AF 1972 Citrullinemia: a new case, with implications concerning adaptation to defective urea synthesis. Pediatr Res 6:626-633
34. Van Thoai N, Roche J 1960 Dérivés guanidiques biologiques. In: Zechmeister $\mathrm{L}$ (ed) Progress in the Chemistry of Organic Natural Products, Vol 18. Springer-Verlag, Vienna, pp 83-121

35. Natelson S, Sherwin JE 1979 Proposed mechanism for urea nitrogen reutilization: relationship between urea and proposed guanidine cycles. Clin $\mathrm{Chem}$ 25:1343-1344

\section{Announcements \\ 1990 ANNUAL MEETINGS}

The American Pediatric Society, The Society for Pediatric Research and The Ambulatory Pediatric Association will meet May 7-11, 1990; Anaheim Hilton \& Towers and Convention Center, Anaheim, CA.

Contact: APS or SPR: Association Headquarters, 2650 Yale Blvd., S.E., Suite 104, Albuquerque, NM 87106, (505) 764-9099 or 0068. APA: Ambulatory Pediatric Association, 6728 Old McLean Village, McLean, VA 22101, (703) $556-9222$.

\section{Special Program in Nutrition for a Healthy Heart Developed for Grade School Children and Their Parents}

The J. David Gladstone Foundation of the University of California, San Francisco, has developed a heart healthy nutrition education curriculum for third grade students and their parents. This curriculum, called the Special Program in Nutrition (SPIN), consists of two manuals and a cookbook collection of low fat, low cholesterol recipes. The manuals contain an in-service program for teachers, 27 lessons for third grade students, seven lessons for fourth grade students, and a parents' program with ten planned meetings.

The cost of the complete set is $\$ 35.00$; the two-volume curriculum and the cookbook may be purchased separately for $\$ 30.00$ and $\$ 10.00$, respectively. Add $6.5 \%$ California sales tax where applicable. For further information contact: The Gladstone Foundation Laboratories, 2550 23rd Street, P.O. Box 40608, San Francisco, CA 94140, (415) 826-7500. 